Nachbericht zum 93. Deutschen Röntgenkongress, 16.-19. Mai 2012

\title{
Gegensätze verbunden!
}

„Gegensätze verbinden“ lautete das Motto des diesjährigen 93. Deutschen Röntgenkongresses - es wurde eingelöst! In den interdisziplinär angelegten Sitzungen „DRG trifft...." trafen sich die teilweise sehr unterschiedlichen medizinischen Fachrichtungen, um Gemeinsamkeiten zu entdecken und Gegensätze zu verbinden. Insgesamt fünf Schwerpunktthemen fanden ihren Platz, sie reichten von der Nuklearmedizin bis zur Kinderradiologie.

Die Zahl der Besucher spricht dafür, dass der Deutsche Röntgenkongress in Hamburg angekommen ist: Nach dem Debut im letzten Jahr fanden 2012 insgesamt 7500 Besucher ihren Weg in das Congress Center Hamburg (CCH) und erlebten 4 spannende Kongresstage. In der aktuellen Hamburger In-Location „Schuppen 52“ direkt am Hafen eröffnete Kongresspräsident Prof. Dr. Hermann Helmberger aus München am Mittwochabend den Kongress mit einem Gruß aus seiner bayerischen Heimat. So wurde auch der geografische Gegensatz zwischen Nord und Süd erfolgreich verbunden.

Mit der diesjährigen Röntgenvorlesung, unbestritten ein Highlight jedes Röntgen-

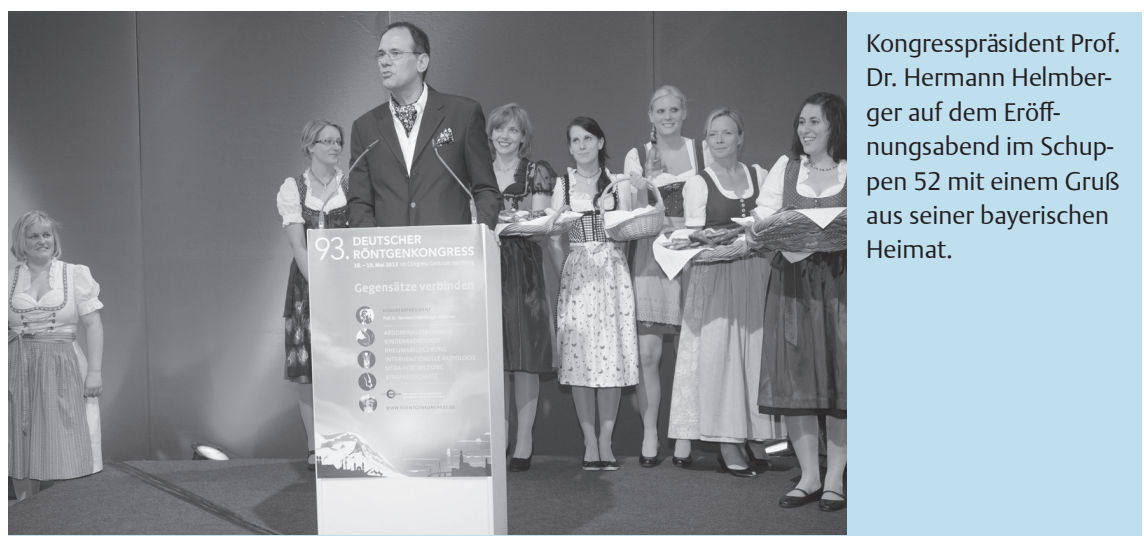

kongresses, gelang eine weitere großartige Verbindung: Richard L. Baron, ein Pionier der Leberbildgebung, reiste extra über den großen Teich nach Hamburg, um über „The Evolution of Liver Imaging: The Search for the Holy Grail“ zu sprechen. Für seinen Vortrag, der die radiologische Diagnostik der Leber von ihren Anfängen bis zur Gegenwart aufzeigte sowie die wissenschaftlichen und kommunikativen Herausforderungen an die Radiologie im Allgemeinen skizzierte, gab es minutenlangen Applaus.

Im Rahmen der Röntgenvorlesung löste sich auch eine lange bestehende VerbinBernhard Lewerich, Geschäftsführer der Deutschen Röntgengesellschaft e.V. von 1999 bis 2012, tritt nach 13 Jahren in den wohlverdienten Ruhestand. Im Rahmen seines Engagements für das Geburtshaus Wilhelm Conrad Röntgens in RemscheidLennep, das die Deutsche Röntgengesellschaft im Mai 2011 erworben hat, wird er der radiologischen Zunft jedoch erhalten bleiben.

Die MTRA als unverzichtbarer Teil der radiologischen Medizin hatten erneut ihren dung, wenn auch nicht ganz: Dipl.-Theol.

Zahlen-Statistik
- Gesamtbesucher: 7500
- Ärzte, Medizintechniker: 3750
- MTRA: 1500
- Studenten: 500
- Industrie: 1750

festen Platz im Programm. Über 1500 Teilnehmerinnen und Teilnehmer füllten den Saal Bucky sowie die Praxisseminare im Universitätsklinikum Hamburg Eppendorf. Die VMTB traf mit ihrer Programmgestaltung damit erneut voll ins Schwarze.

Neben Radiologen und MTRA fand auch der potenzielle Nachwuchs seinen Weg an die Alster: 500 Medizinstudenten schnupperten in die Radiologie hinein im eigens für sie stattfindenden Programm „Radiologie für Studenten“. 180 davon waren zudem Stipendiaten des Programms „die hellsten Köpfe für die Radiologie“ - so viele wie noch nie zuvor. Damit stehen die Zeichen gut für eine erfolgreiche Zukunft der Radiologie und damit auch für den 94. Deutschen Röntgenkongress, der unter eben diesem Motto „Radiologie ist $\mathrm{Zu}$ kunft" kommendes Jahr in Hamburg stattfinden wird.

Bitte jetzt schon vormerken: Der Röntgenkongress 2013 bricht mit einer langen Tradition und wird nicht über den Himmelfahrtstag, sondern über Fronleichnam stattfinden. Merken Sie sich daher jetzt schon den Termin des 94. Deutschen Röntgenkongresses vor: 29. Mai-01.Juni 2013.

Umfangreiches Bildmaterial sowie eine Liste der Preisträger des 93. Deutschen Röntgenkongresses finden Sie auf www. drg.de. 